\title{
AlienaçÃo, IDEOLOGIA E VERDADE NA OBRA DE HANNAH ARENDT
}

\section{[ALIENATION, IDEOLOGY AND TRUTH IN HANNAH ARENDT'S WORK]}

Geraldo Adriano Emery Pereira Professor da Universidade Federal de Viçosa

DOI: http://dx.doi.org/10.21680/1983-2109.2018v25n48ID14775

Natal, v. 25 , n. 48

Set.-Dez. 2018, p. 195-216

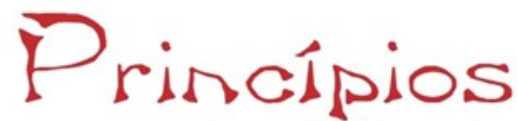

Revista de filosofia 
Resumo: O artigo mostra o lugar da categoria arendtiana de alienação como um operador conceitual na compreensão dos conceitos de ideologia e verdade dos fatos. A noção de alienação permite situar num quadro conceiual a expressão "lógica de uma ideia", que marca o modo como Arendt delimita sua noção de ideologia. Da mesma forma quando vista em relação ao conceito de alienação, a narrativa da verdade dos fatos implica uma atuação de resistência frente ao estatuto moderno de verdade gestado no contexto das alienações modernas. Nesse sentido, a alienação figura como pano de fundo da construção dessas duas elaborações conceituais na obra arendtiana.

Palavras-chave: Alienação; Ideologia; Verdade; Política.

\begin{abstract}
The article shows the place of the Arendtian category of alienation as a conceptual operator in understanding the concepts of ideology and truth of facts. The notion of alienation allows us to place within a conceptual framework the expression "logic of an idea", which marks the way Arendt delimits his notion of ideology. In the same way, when viewed in relation to the concept of alienation, the narrative of the truth of the facts implies an act of resistance against the modern statute of truth born in the context of modern alienations. In this sense, alienation forms the background of the construction of these two conceptual elaborations in the Arendtian work.
\end{abstract}

Keywords: Alienation; Ideology; Truth; Politics. 
Na obra de Hannah Arendt, os temas da ideologia e da verdade, ainda que nem sempre muito citados, podem figurar como duas categorias importantes para a compreensão do modo como a autora pensa os impasses políticos experimentados na era moderna, principalmente nos eventos do mundo moderno do século XX. A proposta de leitura que gostaria de sugerir é que a noção arendtiana de alienação esclarece conceitualmente as noções de ideologia e verdade, e essa situação permite fazer dessas duas categorias uma chave de leitura para a compreensão da reflexão que Arendt faz sobre as experiências políticas modernas. Nesse contexto, indico também que ao atualizar o tema da relação entre a verdade e a política, Arendt situa a verdade dos fatos como aquela que diretamente se relaciona com os negócios humanos. Nessa relação, mesmo não sendo de natureza política, no contexto de uma alienação do mundo e, consequentemente, no plano de uma determinação e manejo da realidade pela ideologia e pela mentira, a verdade dos fatos parece atuar politicamente e, nesse caso, sob a forma política da resistência.

\section{Sobre a noção de alienação}

O tema da alienação, debatido em $A$ condição humana, aparece na reflexão da autora ligado às análises que ela faz sobre a modernidade. Arendt (2013, p. 309) situa as precondições da modernidade em torno de três eventos: a descoberta da América, a reforma protestante e a invenção do telescópio. Para ela, eles são muito importantes na configuração do cenário da modernidade, pois "não são ideias, mas eventos que mudam o mundo" (Arendt, 2013, p. 340). Em síntese, esses eventos implicam três movimentos que fazem o contorno da face do que ela qualifica como era moderna. Respectivamente, eles se referem à ampliação do mundo conhecido, seguida de um processo de redução das distâncias; a expropriação da propriedade e intensificação dos processos de produção e consumo; e, por fim, um avanço "na instrumentalidade experimental" do conhecimento para além daquilo que os sentidos nos 
revelam, seguido de uma desconfiança na objetividade da realidade por meio de um recuo para as certezas da interioridade dos processos da mente e de fabricação ${ }^{1}$.

Para a autora, esses três eventos projetam uma experiência de alienação, e para se compreender essa afirmação é cabal considerar que, para Arendt, alienação refere-se a distanciamento e perda. Na nota número 2 do capítulo VI - "A vita activa e a era moderna" -, da obra A condição humana, ao comentar a análise de Weber sobre a ética protestante e como ela muda a relação do homem com o mundo, ela pondera que "o aumento do poder do homem sobre as coisas deste mundo resulta, em ambos os casos, da distância que ele coloca entre ele mesmo e o mundo, ou seja, da alienação do mundo" (Arendt, 2013, p. 314). De maneira geral, no curso da obra, o termo alienação aparecerá em vários momentos com essa conotação de distância, perda e saída. E, de maneira muito enfática, o que se afirmará acerca da condição moderna é a distância ou perda de um lugar no mundo.

No caso da chegada dos europeus à América, há um complexo processo de agigantamento e perda das distâncias - perde-se o mistério do mundo. A exploração do "novo" continente, que visava ampliar os limites do globo, resultou na compressão das distâncias pelo impulso à velocidade; o que era gigante passa a caber no espaço de nossa sala, o globo ${ }^{2}$. Segundo Arendt, no caso da exploração do globo, com a progressiva diminuição das distâncias, essa "diminuição de distância terrestre só pode ser conquistada ao preço de se colocar uma distância decisiva entre o homem e a Terra, de aliená-lo do seu ambiente terrestre imediato" (Arendt, 2013, p. 313).

No caso da Reforma Protestante, seguida das expropriações que impulsionaram o capitalismo, muitos são destituídos do seu lugar no mundo, e a relação com o mundo, enquanto coisas produzidas

${ }^{1}$ Cf. Arendt, 2013, p. 309-312.

${ }^{2}$ Cf. Arendt, 2013, p. 312. 
pelas mãos dos homens, perde o sentido da durabilidade e passa a ser assumida na perspectiva do consumo. A Reforma, tal como no movimento resultante da descoberta da América, também é seguida de uma alienação. Segundo a autora, esse evento "terminou por nos colocar ante um fenômeno semelhante de alienação" (Arendt, 2013, p. 313). Comparando com a descoberta da América, ela observa que "essa alienação intramundana nada tem a ver, em intenção ou conteúdo, com a alienação em relação à Terra inerente à descoberta e à posse do planeta" (Arendt, 2013, p. 313). Assim, de maneira mais precisa, a Reforma opera uma alienação do tipo expropriação, pois

[...] a propriedade, distintamente da riqueza e da apropriação, indica a parte de um mundo comum que tem um dono privado e é, portanto, a mais elementar condição política para a mundanidade do homem. Pelo mesmo motivo, a expropriação e a alienação do mundo coincidem, e a era moderna, muito contra as intenções de todos os atores da peça, começou por alienar do mundo certas camadas da população. (Arendt, 2013, p. 315)

Nesse cenário, completa o quadro dos eventos geradores desse processo de alienação a invenção do telescópio, que parece ser, para Arendt, o evento principal da modernidade. Segundo ela, mesmo sendo o menos percebido de todos, parece, pelas possibilidades que abriu, ter eclipsado os efeitos das outras duas formas de alienação ${ }^{3}$. No caso dele, a alienação refere-se a um distanciamento, como uma espécie de recuo, em relação ao próprio mundo. Nesse evento, Arendt sugere uma mudança no ponto de vista do conhecimento do mundo. Ao usar o parâmetro do ponto de vista arquimediano, ela sugere que esse ponto, com o telescópio, passa a se localizar fora da terra, ou seja, posso me posicionar, inclusive, fora do planeta para conhecer o próprio planeta. O que essas noções sugerem é uma experiência de distanciamento, perda, e, ou recusa.

${ }^{3}$ Cf. Arendt, 2013, p. 311. 
Diante dessa constatação, Arendt coloca ênfase nos efeitos, pouco declarados pela historiografia tradicional, da descoberta e uso do telescópio ${ }^{4}$ Para ela, "não foi a razão, mas um instrumento feito pela mão do homem, o telescópio, que realmente mudou a concepção física do mundo" (Arendt, 2013, p. 342). Assim, o que conduziu o homem ao novo tipo de conhecimento não foi a contemplação nem a observação, mas as atividades de fazer e fabricar $^{5}$. Na leitura de Arendt, a experiência com o telescópio coloca em colapso a confiança no conhecimento, pois revela uma grande desconfiança na nossa experiência com a realidade que nos alcança. E, de maneira geral, altera a noção de conhecimento e o modo de acesso à verdade.

Para ela, a dúvida cartesiana, com toda a sua radicalidade, evidencia o que essa descoberta provocou, ou seja, uma suspeita sobre a nossa relação com a realidade, com aquilo que alcança os nossos sentidos. Nesse contexto, o desespero em relação ao que podemos conhecer ganha amparo e consolo num recuo da experiência sensorial e fenomênica para a interioridade segura da mente, de modo que a certeza do cogito passa a ser o ponto de segurança do que podemos conhecer e certificar. Nesse sentido, o estatuto do conhecimento e da verdade passa a ser considerado a partir de coisas que nossa mente pode produzir, isto é, só posso conhecer aquilo que produzo. Ou seja, há uma suspeita cada vez maior sobre aquilo que não é resultado das operações mentais, sobre aquilo que é a realidade sensorialmente estabelecida. Segundo ela, o vigor da matemática e o da produção são situações que testemunham essa desconfiança na realidade sensorial, seguida da confiança e abrigo de certeza no plano das realidades imateriais e não contraditórias da mente.

4 "Foi um instrumento, o telescópio, uma obra das mãos do homem, que finalmente forçou a natureza, ou melhor, o universo a revelar seus segredos" (Arendt, 2013, p. 362).

${ }^{5}$ Cf. Arendt, 2013, p. 342. 
A convicção de que a verdade objetiva não é dada ao homem e que ele só pode conhecer aquilo que ele mesmo faz não advém do ceticismo, mas de uma descoberta demonstrável e, portanto, não leva à resignação, mas a uma atividade redobrada ou ao desespero. A perda do mundo na filosofia moderna, cuja introspecção descobriu a consciência como sentido interior com o qual o indivíduo sente os seus sentidos e verificou que ela era a única segurança da realidade, difere não só em grau da antiga suspeita dos filósofos em relação ao mundo e aos outros com quem compartilhavam o mundo; agora, o filósofo já não se volta de um mundo de enganosa perecibilidade para outro mundo de verdade eterna, mas volta as costas a ambos e se retira para dentro de si mesmo. (Arendt, 2013, p. 366)

O abrigo que surgirá nesse limiar da era moderna é o recolhimento na certeza da introspecção, a certeza que se alimenta dos próprios processos da mente, tal como a atitude cartesiana se nutria da certeza gerada pelo próprio ato de duvidar. É nesse sentido que ela sustenta que na era moderna o ponto arquimediano é transferido para o interior da mente, permitindo com isso ao homem libertar-se da realidade, que no caso cartesiano estava sob suspeita ${ }^{6}$.

Segundo Arendt, esses eventos marcam e caracterizam, a título de postura, concepção e relação com a realidade, o que se chama de era moderna ${ }^{7}$. Uma era marcada por um processo de alienação, mais precisamente "pela alienação em relação ao mundo" (Correia, 2014, p. 46). Nos três eventos há ora um distanciamento, ora uma perda, ou uma mudança de perspectiva em relação ao mundo. A

${ }^{6}$ Cf. Arendt, 2013, p. 355.

${ }^{7}$ Mundo e era moderna são termos relacionados, mas diferentes em Arendt. Segundo Alves Neto, "a 'era moderna' começa para Arendt com as revoluções do século XVIII e se caracteriza pela generalização da atividade de fabricação e dos valores do homo faber"; já os três eventos, descoberta da América, a reforma protestante e a invenção do telescópio, aparecem no limiar da era moderna e marcam o seu caráter. "O mundo moderno, por sua vez, é a 'era nova e desconhecida' surgida da passagem do século XIX para o século XX, e determinada pela derrota do homo faber para o animal laborans [...]" (Alves Neto, 2009, p. 52-53). 
ênfase se dá justamente no tipo de alienação que a invenção e uso do telescópio proporcionou, ou seja, um recolhimento na introspecção da mente e uma desconfiança ou desinteresse acerca do mundo que nos afeta pelos sentidos e que partilhamos entre nós ${ }^{8}$.

Em Arendt, a noção de mundo é um operador conceitual importante na compreensão do que ela chama de negócios humanos, e mais precisamente sobre a política. Segundo Alves Neto (2009, p. 19), "o mundo é aquilo que deveria unificar e separar os homens para além dos interesses privados e das necessidades da vida natural"; além disso, "o mundo é o espaço artificial entre o homem e a natureza, bem como o âmbito intermediário de relacionamento e distinção instaurado entre os homens por meio de suas interações comuns". Nesse contexto, a noção arendtiana de mundo implica a pluralidade, uma vez que para a sua constituição é preciso partilhar a perspectiva que cada um tem desse mundo externo que lhe afeta. Segundo Tassin (1989), citando A vida do espírito, na noção arendtiana de mundo não faz sentido pensar em algo ou uma verdade para além das aparências, pois no mundo ser e aparecer coincidem ${ }^{9}$. Nesse caso, o pressuposto do mundo é de fato a pluralidade e não o refúgio da introspecção. Mundo é o que está, portanto, entre nós; ele liga e separa, e a aferição dessa realidade está justamente na partilha das perspectivas, onde ser e aparecer

\footnotetext{
8 “[...] escolher como último ponto de referência a configuração da própria mente humana, que se assegura da realidade e da certeza dentro de um arcabouço de fórmulas matemáticas produzidas por ela mesma. Aqui, a famosa reductio scientiae ad mathematicam permite substituir o que é dado através dos sentidos por um sistema de equações matemáticas nas quais todas as relações reais são dissolvidas em relações lógicas" (Arendt, 2013, p. 355).

9 "Le monde peut être défini comme l'ensemble des choses qui ont en commun de paraître, c'est-à-dire d'être vues, entendues, touchées, senties, goûtées... (V.E., p. 33). Il est ce qu'il paraît, ou encore, selon la formule cardinale d'Arendt, 'Être et paraître coüncident'. Si être et paraître coïncident, l'existence peut être dite la faculté de paraître. Exister est alors apparaître aux regards, être vu: toute vie est le spectacle d'une vie et suppose des spectateurs." (Tassin, 1989, p. 66).
} 
coincidem. Considerando que na noção arendtiana de mundo ser e aparecer coincidem, não cabe aqui a desconfiança cartesiana, tampouco a inquirição acerca do que está para além das aparências dos sentidos, pois, nisso que é a obra de nossas mãos, palavras e feitos, o ser é o que aparece. E isso marca o estatuto do elemento público que constitui o mundo.

Feitas essas considerações, creio ser possível reter que a postura que anima a modernidade, na leitura que Arendt faz da força dos eventos que ela analisa, é a da alienação, ou seja, o distanciamento desse mundo externo que nos afeta pelos sentidos. Mais enfaticamente, pode-se dizer que há um afastamento do que é partilhado na pluralidade de perspectivas, do que é construído no âmbito da palavra e do discurso, pelas coisas e pela estabilidade durável, principalmente pela interação acerca desse mundo como garantia da realidade.

É nesse contexto que penso ser essa noção de alienação o pano de fundo da compreensão arendtiana da ideologia e do problema da verdade dos fatos - essa como uma categoria de resistência na política.

\section{Sobre a noção de ideologia}

A noção de ideologia, que Arendt esclarece no último capítulo de Origens do totalitarismo, ganha mais corpo teórico quando lida à luz das noções arendtianas da alienação como característica que, surgida no limiar da era moderna, parece perpassar o mundo moderno.

Em Origens do totalitarismo, Arendt articula a noção de ideologia, de maneira peculiar, ao que comumente se costuma entender dentro da tradição marxiana, isto é, um ocultamento ou dissimulação do que efetivamente move a realidade material, ou seja, no caso marxiano, a luta de classes. Para Lefort (1990), é o tom de ocultamento e dissimulação que está no cerne da compreensão da ideologia em Marx. 
Marx agarra o princípio da ideologia como modo específico do imaginário, mas não cessa de supor que ela se reduz à dissimulação de alguma coisa: a divisão de classes, a divisão do capital e do trabalho a do Estado e da sociedade civil do presente histórico e suas tarefas sem nunca chegar a pensar que se ela assegura efetivamente essa dissimulação, está comandada e sustentada por um princípio de ocultamento que veio ocupar o lugar daquele que rege o dispositivo simbólico de todas as formações pré-capitalistas. (Lefort, 1990, p. 314)

No contexto da moldura conceitual do significado que Arendt confere à ideologia, ela afirma que as suas potencialidades só foram descobertas na experiência totalitária ${ }^{10}$. Por outro lado, Kateb (2002) vê na leitura que Arendt tem do termo ideologia um distanciamento da compreensão marxiana. Segundo ele, Arendt não aceita o modo como usualmente o termo é concebido na esteira conceitual de Marx, na perspectiva de uma racionalização deliberada ou inconsciente, que justifica os arranjos da realidade política e econômica dos interesses de classe ${ }^{11}$.

Certamente há uma distância entre Arendt e Marx no modo de conceber a ideologia. Entretanto, se retivermos a noção de dissimulação e ocultamento, é possível dizer que Arendt retém de Marx essa consideração ${ }^{12}$, mas radicaliza no tom de autonomia processual da ideologia em relação à realidade. De acordo com ela, a ideologia é o que a palavra indica, ou seja, a lógica de uma ideia.

Uma ideologia é bem literalmente o que seu nome indica: é a lógica de uma ideia. O seu objeto de estudo é a história, à qual a "ideia" é aplicada; o resultado dessa aplicação não é um conjunto de postulados acerca

\footnotetext{
10 "As grandes potencialidades das ideologias não foram descobertas antes de Hitler e de Stalin." (Arendt, 2000, p. 520).

11 "Notice that Arendt does not accept the usual Marx-inspired view that ideology is either deliberate or unconscious rationalization in the sense of offering a justification that is meant to hide the reality of economic and political class-interests." (Kateb, 2002, p. 347)

12 "Marx (and Nietzsche): Again opposition to reality: Ideologies are superstructure destined to veil reality. Or they are justification of certain interests" (Arendt, 1955, p. 024121). V. tb. Arendt, 2008, p. 395.
} 
de algo que é, mas a revelação de um processo que está em constante mudança. A ideologia trata o curso dos acontecimentos como se seguisse a mesma "lei" adotada na exposição lógica da sua "ideia". As ideologias pretendem conhecer os mistérios de todo o processo histórico - os segredos do passado, as complexidades do presente, as incertezas do futuro - em virtude da lógica inerente de suas respectivas ideias. (Arendt, 2000, p. 521)

Nesse sentido, penso que, vista no plano da estrutura teórica da alienação, que marca o caráter da era moderna, fica evidente a força da noção de "lógica de uma ideia". A questão se põe justamente no contexto do embate ou fuga da realidade. No quadro do sistema totalitário, segundo Lefort (1986), a ideologia funciona como uma máquina intelectual que produz consequências a partir de princípios, de maneira a conceber o pensamento inteiramente desconectado da realidade ${ }^{13}$.

Assim, a lógica de uma ideia implica o processo e o movimento da ideia sem relação ou vínculo com a realidade, no sentido da realidade externa das coisas e fatos que partilhamos do mundo que está entre nós. A expressão "lógica de uma ideia" opera e se processualiza dentro do quadro lógico da relação entre verdade e validade. Isso quer dizer que a lógica de uma ideia corresponde à busca de um raciocínio coerente e, portanto, válido ${ }^{14}$, mas que não tem a pretensão de verdade no sentido de uma correção e adequação com os fatos e eventos do mundo que partilhamos entre nós. Margutti Pinto (2001) articula o seguinte exemplo para demonstrar a independência formal da noção de validade da vinculação da

13 “Ce à quoi s'ajoute que ce n'est pás la faculté de commencer, propre aux révolutions, qui se laisse distinguer dans le totalitarisme, mais à l'inverse le triomphe d'une idéologie qui contient la reponse à toute question, tout question qui surgirait des événements; c'est le triomphe d'une machine intellectuelle qui produit les conséquences à partir des principes, comme si la pensée se trouvait déconnectée de l'experience du réel." (Lefort, 1986, p. 65)

${ }^{14}$ No plano lógico, Margutti Pinto (2001) demonstra como a noção de inferência lógica está mais ligada à adequação formal do argumento que necessariamente com a verdade fática das premissas. 
verdade fatual. No exemplo ele usa o seguinte silogismo: "Todo inseto é humano/ toda abelha é inseto/ logo toda abelha é humano". Nessa sentença silogística temos um dos antecedentes falso e o consequente também falso, mas a inferência lógica é válida, pois, ao afirmar que todos os insetos são humanos, todos os insetos estão incluídos na classe dos humanos; ao afirmar que toda abelha é inseto, elas passam a ser incluídas na classe dos insetos. Combinando as duas sentenças, se elas forem verdadeiras, somos autorizados a concluir que a classe das abelhas está na classe dos humanos ${ }^{15}$. Assim, o que se conclui acerca da noção de validade e verdade é que "a validade de uma inferência não depende da verdade ou falsidade das sentenças que constituem o argumento. 'Validade inferencial' não é sinônimo de 'verdade' e um argumento correto não envolve necessariamente sentenças verdadeiras" (Margutti Pinto, 2001, p. 27).

Considerando esse panorama, ao colocar o foco na noção de "lógica de uma ideia", o que Arendt destaca na ideologia é esse movimento formal de uma ideia, que tem sua validade lógica, ou seja, sua coerência, sem depender de uma correção ou adequação com o plano material dos fatos e eventos, ou seja, da realidade. Diante disso, no contexto da alienação moderna, a noção de processos, que ela destaca no texto $A$ condição humana e que, de certa maneira, consta na definição de ideologia presente em Origens do totalitarismo, é pertinente para a compreensão desse assunto. Naquela obra dois processos são destacados: os processos mentais e os processos de fabricação. Ambos têm por característica almejarem uma independência da realidade.

No plano dos processos mentais, o exemplo do raciocínio e das operações matemáticas é emblemático para Arendt. Sobre o raciocínio matemático como um processo mental, ela afirma que

é essa faculdade que a era moderna denomina raciocínio do senso comum; trata-se do jogo da mente consigo mesma, jogo esse que ocorre

${ }^{15}$ Cf. Margutti Pinto, 2001, p. 23. 
quando a mente se fecha contra toda realidade e "sente" somente a si própria. Os resultados desse jogo são "verdades" compulsórias, porque, supostamente, a estrutura mental de um homem difere da de outro apenas na forma do seu corpo. (Arendt, 2013, p. 354)

No plano dos processos de fabricação, a caracterização dos processos não é muito diferente, ou seja, "o que mudou a mentalidade do homo faber foi a posição central do conceito de processo da modernidade" (Arendt, 2013, p. 383). A ênfase no plano da fabricação deixou de ser sobre o produto e passou a ser no processo em si. De modo que, segundo Arendt, passou-se da questão "sobre o que uma coisa é e que tipo de coisa deve ser produzida para a questão sobre como e mediante que meios e processos ela veio a existir e poderia ser reproduzida" (Arendt, 2013, p. 380).

Nesse contexto, se recolocarmos o tema da alienação como distanciamento da realidade e do mundo e o tema da ideologia como lógica, ou processo, de uma ideia, o que poderemos verificar é a ênfase numa espécie de controle e previsibilidade contra a imprevisibilidade constitutiva dos fatos e assuntos humanos, como já reiterava Arendt na definição de ideologia. Segundo ela, é justamente no campo dos assuntos humanos que essa nova filosofia (moderna) se mostrou deficiente ${ }^{16}$, ou seja, no plano das contradições e imprevisibilidades humanas. "A ideia de que só aquilo que vou produzir será real - perfeitamente verdadeira e legítima no domínio da fabricação - é sempre derrotada pelo curso efetivo dos eventos, no qual nada acontece com mais frequência que $\mathrm{o}$ totalmente inesperado." (Arendt, 2013, p. 375)

Assim, a alienação enquanto distanciamento do mundo e, consequentemente, da realidade explica a condição na qual a noção de "lógica de uma ideia", vista como processo mental, resultado da alienação do mundo, opera com força lógica e em distanciamento da realidade. Da mesma maneira que a noção de fabri-

${ }^{16}$ Cf. Arendt, 2013, p. 375. 
cação centrada na autonomia do processo, sem se importar com um telos, também se divorcia da realidade.

Voltando à noção que Arendt desenvolve de ideologia em Origens do totalitarismo, vemos que, lá, natureza e história figuram como os dois eixos processuais, em que a lógica de uma ideia, isto é, o movimento coerente de uma premissa desconexa das contradições e imprevisibilidades da realidade ${ }^{17}$, avança de maneira autônoma da realidade e, no caso do nacional socialismo, avança de maneira infinita, num processo pelo processo, tal como atestam os campos de concentração. Assim:

Para a mentalidade do homem moderno, determinada pelo desenvolvimento da ciência moderna e pelo concomitante desabrochar da moderna filosofia, era pelo menos igualmente decisivo que o homem passasse a se considerar parte integrante dos dois processos sobre-humanos e oniabrangentes da natureza e da história, ambos aparentemente condenados a produzir infinitamente sem jamais alcançar qualquer telos inerente ou aproximar-se de qualquer ideia predeterminada (Arendt, 2013, p. 384)

Por isso, segundo ela, em A condição humana, as noções lógicas de processos históricos ou naturais, são vigorosos como operadores de ideologias que enquadram ou desprezam o confronto com a realidade no plano do ajustamento e do controle da vida, nessa noção de processo como lógica de uma ideia. De maneira geral, a alienação do mundo, isto é, um distanciamento e uma desconsideração da realidade, implica um recuo no tocante à imprevisibilidade que tipifica os eventos e a realidade do mundo. A noção de "lógica de uma ideia" e esse movimento lógico como processo, que formalmente se basta, permite ao aparato ideológico libertarse das contradições e impasses da realidade.

\footnotetext{
17 "Agir nos moldes da atividade de produzir, ou raciocinar nos moldes do 'cálculo de consequências', significa ignorar o inesperado, o próprio evento, uma vez que seria não razoável ou irracional esperar o que não passa de 'improbabilidade infinita” (Arendt, 2013, p. 375).
} 


\section{Sobre a noção de verdade dos fatos}

Arendt é muito clara nos seus textos ao dizer que o tipo de verdade que lhe interessa é aquela cujo oposto é a mentira, e, nesse caso, é a verdade dos fatos. ${ }^{18}$ Em $A$ condição humana, a autora mostra como o telescópio, ao provocar o desespero e a dúvida que se consolida no plano da filosofia cartesiana, altera a relação e a noção geral de verdade. Se no plano da filosofia tradicional a busca pela adequatio pressupunha a separação entre ser e aparência, e nesse caso era necessário transpor a aparência dos sentidos, o desespero gerado pela dúvida cartesiana, relativa ao mundo, aprisiona a verdade no interior do sujeito.

O novo estatuto da verdade perde o tom de objetividade no sentido da adequatio e passa a vigorar no plano do construído e elaborado pelo sujeito. De modo que a clássica hierarquização e oposição entre verdade racional e sensorial, marcada pela superioridade da razão em sua capacidade para contemplar a verdade, perde o sentido diante da implicação de que a verdade e a realidade não são dadas ${ }^{19}$. Assim, Arendt completa sua análise delineando o que se fixará como estatuto da verdade na era moderna, pois, "embora não se possa conhecer a verdade como algo dado e desvelado, o homem pode, pelo menos, conhecer o que ele próprio faz" (Arendt, 2013, p. 353). Assim, o estatuto da verdade passa a vigorar fora da objetividade típica da noção clássica de adequatio ${ }^{20}$ e se estabelece no plano dos processos de fabricação ou das operações mentais. De modo que, no plano desse novo estatuto da

\footnotetext{
${ }^{18}$ Cf. Arendt, 2003, p. 308.

${ }^{19}$ Cf. Arendt, 2013, p. 342.

20 "Que a verdade se revela por si mesma era o credo comum à Antiguidade pagã e à hebraica, à filosofia secular e à filosofia cristã. Por isso, a nova filosofia moderna voltou-se com tamanha veemência - na verdade, com uma violência que se avizinha do ódio - contra a tradição, abolindo sumariamente a entusiasta restauração e a redescoberta da Antiguidade pela Renascença." (Arendt, 2013, p. 344)
} 
verdade, isto é, produzida e não dada ou contemplada, segundo Arendt,

onde antes a verdade residira no tipo de "teoria" que, desde os gregos, significara a mirada contemplativa do expectador que se interessava pela realidade aberta diante de si e a acolhida, a questão do sucesso passou a dominar, e a prova da teoria passou a ser uma prova "prática" - se funcionará ou não. A teoria converteu-se em hipótese e o sucesso da hipótese converteu-se em verdade. (Arendt, 2013, p. 347)

Nesse caso, a verdade passa a se encontrar no teste da hipótese fabricada, pois o que se conhece é aquilo que é capturado pela fabricação, seja nos processos mentais, seja nos processos da instrumentação experimental, pois só se conhece com o auxílio de coisas fabricadas pelas mãos humanas, tal como inaugurado pelo experimento do telescópio. Essa mudança no estatuto da verdade possibilitou grande avanço no conhecimento da natureza, no aprimoramento da tecnologia e, consequentemente, da ciência moderna, porém, se transposta para o âmbito público da ação, paga o alto preço da desconfiança e temor da contingência.

De posse desse quadro teórico, podemos colocar lado a lado as experiências modernas da alienação e as relativas à verdade dos fatos. No caso dessa interação entre essas duas categorias, a figura da mentira parece estar pressuposta nessa relação, pois, nesse tom de alienação do mundo e da realidade, parece restar, a título residual, o pressuposto da veracidade. Segundo Arendt (2013, p. 346), "a perda da certeza da verdade levou a um novo zelo inteiramente sem precedente, pela veracidade". Isso significa dizer que nessas circunstâncias a pressuposição da possibilidade da mentira estava ancorada na sua contradição, isto é, a resistência da realidade, visto que o homem só se poderia permitir ser um mentiroso "enquanto estava seguro da incontestável existência da verdade e da realidade objetiva, que certamente sobreviveriam e derrotariam suas mentiras". Ou seja, é justamente a resistência da realidade e do mundo dos fatos que faz da mentira uma mentira, isto é, a 
mantém separada e em tensão com a condição estabilizadora da verdade dos fatos. É justamente diante do risco moderno de a mentira tornar-se uma "realidade" efetiva ou assumir o lugar da verdade que Arendt indica a figura, bastante adequada ao contexto da alienação do mundo, do autoembuste. ${ }^{21}$

No domínio da política, onde o sigilo e o embuste deliberado sempre tiveram um papel importante, o autoembuste é o perigo por excelência; o impostor autoenganado perde todo o contato, não somente com a sua plateia, mas também com o mundo real, que continuará importunando-o, pois ele pode tirar sua mente dele, mas não pode tirar o seu corpo. (Arendt, 2004, p. 39)

Assim, essa situação de resistência da realidade parece ser o que se fragiliza no curso da era moderna e posteriormente no mundo moderno, chegando ao ponto do risco de uma mentira geral e, por princípio, que obscureça a fronteira entre ficção e realidade - situação que de fato tem por pano de fundo a alienação do mundo. Essa é, portanto, a grande preocupação de Arendt quando mobiliza o debate sobre a relação entre a verdade dos fatos e a política.

A noção de alienação desqualifica os fatos. A desconfiança nos fatos, vista no plano dos processos da mente ou de fabricação, abusa da condição ontológica de contingência. Há um risco apontado na perspectiva da aversão que a racionalidade processual tem pela contingência, e que já está na ideologia - que diz respeito à tentativa de buscar um arsenal lógico para explicar o mundo humano $^{22}$ e, com isso, apagar a linha divisória entre a verdade e a

${ }^{21}$ Em "Verdade e política", Arendt narra uma anedota medieval em que mostra o quanto pode ser difícil mentir para os outros sem mentir para si próprio. Após narrar a estória, ela conclui que "nossa apreensão da realidade depende de nosso compartilhamento do mundo com nossos semelhantes, e quanta força de caráter é necessária para se ater a algo, mentira ou verdade, que não seja compartilhado. Em outras palavras, quanto mais bem sucedido for um mentiroso, maior é a probabilidade de que ele seja vítima de suas próprias invencionices" (Arendt, 2003, p. 314).

${ }^{22}$ Cf. Arendt, 2004, p. 21. 
falsidade. ${ }^{23}$ Para ela, "a falha de tal raciocínio começa em querer reduzir as escolhas a dilemas mutuamente exclusivos, a realidade nunca se apresenta com algo tão simples como premissas para conclusões lógicas" (Arendt, 2004, p. 21). A noção de alienação como distanciamento da realidade, introspecção e apego aos processos lógicos dá vigor aos mentirosos. As mentiras podem seguir a precisão e a previsibilidade da lógica de uma ideia e da noção de "processos mentais". Nesse sentido, o mentiroso narra o que se espera que seja, de maneira coerente. Já os fatos são contraditórios, contingentes e imprevisíveis; são, no plano da realidade e da postura moderna da alienação, objeto de desconfiança e de distanciamento. Nesse sentido, a advertência de Arendt é que

a história é uma estória de eventos, e não de forças ou ideias em curso previsíveis. São ociosas e até perigosas quando empregadas como argumento contra a realidade, ou quando se destinam a indicar potencialidades e alternativas positivas, visto que não apenas o seu número é ilimitado por definição, mas também lhe falta a tangível inesperabilidade do evento que elas procuram compensar com a mera plausibilidade. (Arendt, 2013, p. 314)

Assim, ao falar dos riscos da mentira organizada, tema que pode ser visto em Origens do totalitarismo, "Verdade e política" e "Mentira na política", o que Arendt mostra é a potencialização política dessa condição de alienação do mundo e, consequentemente, de distanciamento da realidade, principalmente pela confiança de que só conhecemos aquilo que produzimos e, numa certa medida, desconfiamos das contradições dos fatos. Nesse tipo de desconfiança, no plano da política, a alienação e a propaganda

\footnotetext{
23 "Em outras palavras, o resultado de uma substituição coerente e total da verdade dos fatos por mentiras não é passarem estas a ser aceitas como verdade, e a verdade ser difamada como mentira, porém um processo de destruição do sentido mediante o qual nos orientamos no mundo real - incluindo-se entre os meios mentais para esse fim a categoria de oposição entre verdade e falsidade." (Arendt, 2003, p. 318)
} 
avançam sobre essa possibilidade, de que, diante da alienação do mundo, ou seja, sem essa resistência da realidade contra as mentiras, mentir em massa, em geral e por princípio, coloca em risco o estatuto da realidade, isto é, pode, mais que dissimular, apagar a linha divisória entre ficção e realidade, e, no contexto da experiência totalitária, realmente parecerá que "every thing is possible". Por isso, nesse contexto, mesmo não sendo uma categoria política, a verdade dos fatos, quando narrada, onde todos mentem e o fazem por princípio, atua politicamente, pois nesse caso o que diz a verdade, segundo Arendt, começa a agir ${ }^{24}$.

Em síntese, esse tom de resistência da narrativa da verdade dos fatos parece ser configurado quando Arendt qualifica o que na relação com a política ela descreve como verdade. Segundo ela, a política é limitada por aquelas coisas que não podemos modificar à vontade $^{25}$; com isso, conceitualmente, "podemos chamar verdade aquilo que não podemos modificar" (Arendt, 2003, p. 325). Essa posição de Arendt sobre a verdade, na sua relação com a política, situa o contraponto à noção de verdade que está inserida no contexto da alienação presente nos processos de fabricação e na introspecção da mente. Nessas duas situações, o estatuto da verdade está no produzido e, portanto, controlável e modificável, ao passo que a verdade que tensiona com a política é a que não pode ser modificada à vontade. Marcar essa condição da verdade - seja

\footnotetext{
24 "Jamais se incluiu a veracidade entre as virtudes políticas, pois ela de fato pouco contribui para esta transformação do mundo e das circunstâncias, que é uma das mais legítimas atividades políticas. Somente quando uma comunidade adere ao mentir organizado por princípio, e não apenas em ralação a particularidades, a veracidade como tal, sem o apoio das forças distorcivas do poderio e do interesse, se torna fator político de primeira ordem. Onde todos mentem acerca de tudo que é importante aquele que conta a verdade começou a agir; quer ele saiba ou não, ele se comprometeu também com os negócios políticos, pois, na improvável eventualidade de que sobreviva, terá dado um primeiro passo para a transformação do mundo." (Arendt, 2003, p. 311) ${ }^{25}$ Cf. Arendt, 2003, p. 325.
} 
num mundo do homo faber, seja no do animal laborans - é a marca da atuação política da verdade dos fatos como resistência.

\section{Considerações finais}

O que se pretendeu com o texto foi mostrar como o conceito de alienação, presente em $A$ condição humana, opera uma importante chave de compreensão das categorias de ideologia e verdade dos fatos. Numa certa medida, a noção de alienação permite duas aproximações junto aos temas da ideologia e da verdade dos fatos. Com relação à primeira, possibilita visualizar com clareza o tom da expressão "lógica de uma ideia", típica da definição arendtiana de ideologia, isto é, um processo autônomo em relação à realidade, marcado pelo movimento da ideia como um processo fechado em si mesmo. A segunda permite qualificar a atuação política da verdade dos fatos, ou seja, como uma resistência à inserção dos processos modernos no campo da política, isto é, uma modificação ilimitada, pautada no estatuto moderno da verdade, como algo construído e, portanto, controlável. Nesse sentido, a verdade dos fatos é um contraponto e, logo, uma resistência a uma previsibilidade processual, que ameaça a contingência típica dos assuntos humanos.

\section{Referências}

ALVES NETO, Rodrigo Ribeiro. Alienações do mundo: uma interpretação da obra de Hannah Arendt. São Paulo: Loyola, 2009.

ARENDT, Hannah. Ideologies - seminar 1955 (Courses - University of California). The Hannah Arendt papers at the Library of Congress. Washington (DC): Library of Congress, [1955]. 8f. Disponível em: $<$ http://memory.loc.gov/cgi-

bin/ampage collId $=$ mharendt_pub\&fileName $=04 / 040630 / 040630$ page . db\&recNum $=31>$. Acesso em: 30 jun. 2018. 
ARENDT, Hannah. Origens do totalitarismo: antisemitismo, imperialismo, totalitarismo. Trad. Roberto Raposo. São Paulo: Companhia das Letras, 2000.

ARENDT, Hannah. Entre o passado e o futuro. São Paulo: Perspectiva, 2003.

ARENDT, Hannah. Crises da república. Trad. José Volkmann. São Paulo: Perspectiva, 2004.

ARENDT, Hannah. Compreender: formação, exílio e totalitarismo. Trad. Denise Bottman. São Paulo: Companhia das Letras; Belo Horizonte: UFMG, 2008.

ARENDT, Hannah. A condição humana. Trad. Roberto Raposo. 11. ed. Rev. Apres. Adriano Correia. Rio de Janeiro: Forense Universitária, 2013.

CORREIA, Adriano. Hannah Arendt e a modernidade: política, economia e a disputa por uma fronteira. Rio de Janeiro: Forense Universitária, 2014.

KATEB, George. Ideology and storytelling. Social Research. v. 69, n. 2, Summer 2002, p. 321-357.

LEFORT, Claude. Essais sur le politique XIX-XX siècles. Paris: du Seuil, 1986.

LEFORT, Claude. As formas da história: ensaios de Antropologia Política. Trad. Luiz Roberto Salinas Fortes e Marilena de Souza Chauí. São Paulo: Brasiliense,1990. p. 295-345.

MARGUTTI PINTO, Paulo Roberto. Introdução à lógica simbólica. Belo Horizonte: UFMG, 2001.

TASSIN, Etienne. La question de l'apparence. In: ABENSOUR, Miguel; BUCI-GLUCKSMANN, Christine; CASSIN, Barbara; COLLIN, Françoise; D'ALLONNES, Myriam Revault. (Ed.). Ontologie et politique: actes $d u$ Colloque Hannah Arendt. Paris: Tierce, 1989. p. 63-84. 
216

Alienação, ideologia e verdade

Artigo recebido em 30/06/2018, aprovado em 12/07/2018

Princípios:Revista de Filosofia, Natal, v. 25, n. 48, set.-dez.2018. ISSN1983-2109 